\title{
SEROPREVALENCIA DEL VIRUS DE LA LEUCOSIS VI RAL BOVINA EN ANI MALES CON TRASTORNOS REPRODUCTIVOS DE MONTERÍA
}

\section{SEROPREVALENCI A OF BOVI NE LEUKEMI A VI RUS IN ANI MALS WITH REPRODUCTI VE PROBLEMS IN MONTERIA}

\author{
César Betancur $\mathrm{H},{ }^{\star 1} \mathrm{M} . \mathrm{Sc}$, Juan Rodas $\mathrm{G},{ }^{2} \mathrm{Ph}$.D. \\ ${ }^{1}$ Universidad de Córdoba, Facultad de Medicina Veterinaria y Zootecnia. Montería, Colombia. \\ Departamento de Ciencias Pecuarias. Montería-Córdoba. ${ }^{2}$ Universidad de Antioquia, Facultad de \\ Ciencias Agrarias, Medellín, Colombia. *Correspondencia: betanci@yahoo.com
}

Recibido: Octubre 23 de 2007; Aceptado: Marzo 13 de 2008.

\section{RESUMEN}

Objetivo. Determinar la seroprevalencia de Leucosis Viral Bovina (LVB) en animales con trastornos reproductivos. Materiales y métodos. Se recolectaron 137 muestras de sangre de hembras con antecedentes de infertilidad, pertenecientes a 28 fincas distribuidas en el municipio de Montería; adicionalmente, se obtuvieron muestras al azar de 26 toros pertenecientes a las mismas fincas que fueron analizadas para anticuerpos contra LVB. La técnica serológica empleada fue la prueba de ELISA. Se realizó un análisis descriptivo tabulando la información con datos de seropositividad y seronegatividad obtenidos de cada animal; los resultados se interpretaron de acuerdo a las variables: raza, edad, sexo, zona, tipo de explotación y evento o problema reproductivo detectado. Para determinar la asociación entre seropositividad y cada una de las variables se utilizó la prueba de $\chi^{2}$. Resultados. Las pruebas arrojaron una seroprevalencia del $21 \%$ para LVB. No se encontraron diferencias significativas de prevalencia asociadas a las variables raza, edad o estado reproductivo de los animales $(p \geq 0.05)$, pero si entre la presencia de anticuerpos contra LVB y las variables zona, tipo de explotación y sexo. Conclusiones. Se demuestra la circulación del virus de la LVB en Montería, (Colombia). Se confirma la importancia de implementar un programa de control y prevención de la diseminación de la infección, con el fin de evitar las pérdidas económicas asociadas, y dentro de lo posible, la eliminación de los especímenes seropositivos para lograr la erradicación de la infección en esta zona del país.

Palabras clave: Leucosis, bovinos, virus, reproducción, Córdoba. 


\section{ABSTRACT}

Objective. To determine the seroprevalence of bovine leukemia virus (BLV) in animals with reproductive problems. Materials and methods. Blood samples were collected from 137 cows with a history of infertility, belonging to 28 farms distributed in the municipality of Monteria; additionally, samples were obtained at random from 26 bulls from the same farms that were analyzed for antibodies against bovine leukemia virus (BLV). The serological technique used was ELISA. A descriptive analysis was made tabulating the information with seropositive and seronegative data obtained from each animal; results were interpreted according to the variables: race, age, sex, zone, type of exploitation and the event or reproductive problem detected. To determine the association between seropositivity and each of the variables the $\chi^{2}$ test was used. Results. Analysis showed a seroprevalence of $21 \%$ for bovine leukemia virus (BLV). There were not significant differences in prevalence associated with race, age or reproductive state of animals $(p \geq 0.05)$ variables, but there were among the presence of antibodies against BLV and zone, type of exploitation and sex variables. Conclusions. The results obtained demonstrate the circulation of bovine leukemia virus (BLV) in Montería, Córdoba (Colombia) and confirm the importance of implementing a control program and prevention of dissemination of infection, with the purpose of avoiding economic losses associated with BLV infection and, where possible, elimination of seropositive animals to eradicate the infection from this region of Colombia.

Key words: Leukocis, bovines, virus, reproduction, Cordoba.

\section{NTRODUCCI ÓN}

El virus de la Leucosis Viral Bovina (LVB) es un retrovirus asociado a la leucosis bovina enzoótica, enfermedad de distribución mundial y largo período de incubación, que se presenta especialmente en ganado adulto (1).

La vía habitual por la que el virus se propaga en condiciones naturales es la transmisión horizontal; prácticas que impliquen la manipulación del ganado como el descornar sin desinfectar, la palpación con mangas no desechables (2) y la antigua práctica de la premunición (transfusión de sangre de animales adultos a jóvenes, para favorecer la "estabilidad enzoótica" por babesia y el anaplasma), han favorecido la diseminación de la infección, particularmente en los hatos lecheros (transmisión iatrógena) cuando se realizan sin respetar las medidas higiénicas. Aunque usualmente, los terneros nacidos de vacas seropositivas para la LVB sufren por lo general infección congénita debido a la exposición transplacentaria del virus durante la gestación (3); el virus se encuentra principalmente en los linfocitos y puede identificarse en sangre, leche y otros fluidos corporales, como el semen (4).

Una de las formas clínicas más asociadas con su presencia, es una neoplasia maligna denominada linfosarcoma que se caracteriza por la aparición de cúmulos de linfocitos neoplásicos en casi todos los órganos (5). En Colombia la LVB se identificó por primera vez en 1957 a partir de casos clínicos y de necropsia llegados a centros de diagnóstico veterinarios (6).

Otra forma de presentación clínica de la infección, es una linfocitosis persistente (LP), o proliferación benigna de células linfoides. Sin embargo, sólo una fracción del ganado que llega a ser infectado con LVB desarrolla linfosarcoma y LP (7). Por muchos años, el diagnóstico de infección por LVB fue basado solamente en métodos hematológicos, consistentes en el conteo de leucocitos; aunque la LP fue un indicador de infección 
por LVB, los exámenes hematológicos no identifican todo el ganado infectado (1).

Entre las pruebas serológicas para el LVB, la inmunodifusión en gel de agar ha sido tradicionalmente usada, como el método estándar para detectar animales infectados (8). Los estudios, basados en la prueba de inmunodifusión doble en agar, han mostrado reactividad variable para diferentes regiones y sistemas de producción. En este sentido, Griffiths et al (9) encontraron prevalencias en ganado de leche de $24.9 \%$ para la región Andina, $\quad 14.4 \%$ para la región Caribe y $15.3 \%$ para el Piedemonte Llanero (10).

En el departamento de Córdoba en un estudio de prevalencia hecho sobre 104 fincas de bovinos doble propósito sobre 2909 animales en 1991, se encontró una prevalencia de $1.5 \%$ para LVB (10). En otro estudio en este mismo departamento en los municipios de Cereté, San Carlos y Momil, se reportó un $15 \%$ de seroprevalencia con la técnica de ELISA (11).

Recientemente se ha ensayado la prueba de ELISA, para establecer programas de control y erradicación. Como la diseminación natural de LVB ocurre a una tasa relativamente baja entre el ganado susceptible y el virus es diseminado por movimiento de animales infectados de una manada a otra dentro de un hato, se han llevado a cabo intentos para establecer hatos de ganado libres de LVB en Finlandia (12) y más recientemente en Corea (7), usando la prueba de ELISA.

La LVB es importante económicamente no sólo por la pérdida de mercado para exportación que requiere ganado libre de LVB, sino también por los costos en que se incurre para el diagnóstico, por la muerte prematura de algunos animales como resultado del linfosarcoma y la pérdida de canales en mataderos (13).

También es importante en salud pública, ya que la infección se ha transmitido a humanos al consumir leche de vacas infectadas. Existe un reporte sobre la presencia del antígeno gp 51 (glicoproteína de superficie) del virus de la LVB en el 7\% de los casos de cáncer de seno, lo que sugiere que este virus es capaz de infectar células humanas (14). Uno de los efectos más difíciles de medir pero también uno de los más importantes, es la deficiente respuesta de los animales infectados a otras infecciones bacterianas y virales y por lo tanto los gastos en tratamientos o las fallas post-vacunales y las pérdidas indirectas por efectos sobre la capacidad reproductiva (15).

El objetivo del presente estudio fue determinar la prevalencia de anticuerpos contra el virus de la LVB en vacunos y establecer si existe una mayor prevalencia en aquellos con problemas reproductivos.

\section{MATERI ALES Y MÉTODOS}

Sitio de estudio. El trabajo se desarrolló en el municipio de Montería, departamento de Córdoba, cuya temperatura promedio oscila entre $28^{\circ}$ y $35^{\circ} \mathrm{C}$, humedad relativa del $85 \%$ y una precipitación anual de $1200 \mathrm{~mm}$. El área municipal de $3.043 \mathrm{Km}^{2}$, está conformada por 27 corregimientos, y limita al Norte con Puerto Escondido, San Pelayo y Cereté, al Este con San Carlos y Planeta Rica, al Sur con Tierralta y Valencia y al Oeste con Canalete y con el departamento de Antioquia (16).

Tipo de estudio y tamaño de la muestra. La investigación propuesta correspondió a un estudio epidemiológico de tipo descriptivo de corte transversal. El tamaño de la muestra se determinó mediante el programa estadístico EPI-INFO 2000 versión 6.0 CDC, Atlanta, GA, USA y correspondió a 163 bovinos. Se recolectaron muestras de sangre de 137 hembras bovinas y 26 toros provenientes de 28 fincas distribuidas en el municipio de Montería, Córdoba, Colombia. Este municipio declaró al momento del estudio una población de 178.320 hembras mayores de 2 años (17).

Selección de la muestra. Como criterios de inclusión se tuvo en cuenta que las hembras fueran repetidoras (más de tres servicios sin gestación) y/o que tuvieron reporte de abortos (tempranos o tardíos) o de reabsorción embrionaria. Estas situaciones fueron constatadas a través de las 
evaluaciones reproductivas rutinarias que se adelantaron en cada explotación. En cada finca se tomó muestras a 5 hembras que cumplían con por lo menos uno de los criterios de inclusión y a por lo menos 1 toro con o sin lesiones compatibles con la infección por LVB al examen clínico. Se obtuvo información referente a identificación del animal, edad, raza, tipo de explotación y estado reproductivo, variables necesarias para la correlación con la seropositividad a LVB.

\section{Obtención del suero y procesamiento de} las muestras. Previa desinfección del área y adecuada sujeción del animal, se obtuvieron $5 \mathrm{ml}$ de sangre por venopunción yugular con tubos tipo vacutainer sin anticoagulante. Los animales muestreados fueron hembras bovinas mayores de dos años de edad procedentes de cualquier sistema de producción. El procesamiento de las muestras se realizó en el laboratorio veterinario Azumendi de Bogotá, y los sueros fueron probados mediante la técnica de ELISA utilizando el kit de laboratorios IDEXX (Barcelona, España). Este kit se emplea para la detección immunoenzimática de anticuerpos contra el VLB en suero, utilizando un antígeno de LVB y un antígeno celular control. Las muestras cuyos valores fueron mayores o iguales a 0.50 de densidad óptica con una longitud de onda de $450 \mathrm{~nm}$, se consideraron positivas y las inferiores a este valor negativas (18).

Análisis estadístico. Para los análisis estadísticos se utilizó el coeficiente de contingencia de Pearson, el cual utiliza la distribución $\chi^{2}$ para determinar posibles asociaciones. Para la obtención de resultados de las distintas variables se utilizó el paquete estadístico SPSS versión 11 (19).

\section{RESULTADOS}

En la figura 1 se observa que de las 163 muestras examinadas, se detectaron 35 animales positivos a la LVB (21\%).

Este resultado (21.5\%) es similar al obtenido por otros investigadores (9) en la región

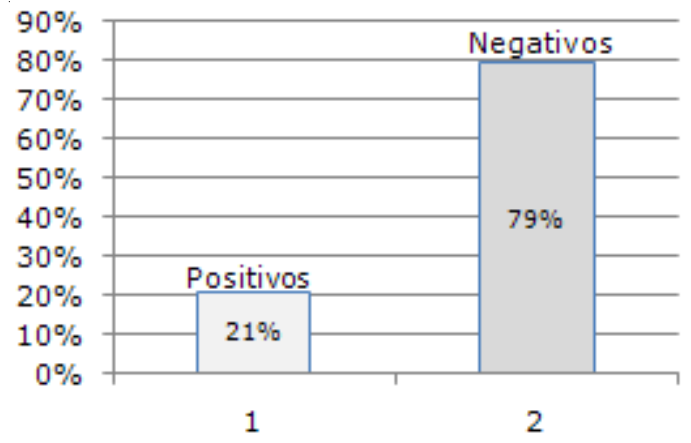

Figura 1. Porcentaje de animales positivos y negativos a LVB ( 1 =positivos $2=$ negativos).

Andina (24.9\%); pero superiores a los encontrados en la costa Caribe (1.5\%) (10) y $(15.3 \%)(11)$.

Análisis de las variables. La tabla 1 se muestra la procedencia por zonas de los 163 especimenes recolectados en el municipio de Montería. Como se observa en la tabla 1 la zona Este presentó la mayor frecuencia de animales positivos 13/40 (32.5\%); el análisis estadístico para la variable zona resultó significativo $\left(\chi^{2}: 7.898, p=0.048\right.$, $\mathrm{p} \leq 0.05)$; lo cual significa que existen diferencias estadísticas entre las frecuencias de infección dependiendo de la zona de

Tabla 1. Seropositividad a LVB en cuatro zonas del municipio de Montería.

\begin{tabular}{lcc}
\hline \multirow{2}{*}{ ZONA } & \multicolumn{2}{c}{ Animales seropositivos } \\
\cline { 2 - 3 } & No (\%) & $\%$ del total \\
\hline Norte & $11 / 40(27.5)$ & 31.4 \\
Oeste & $7 / 40(17.5)$ & 20.0 \\
Este & $13 / 40(32.5)$ & 37.1 \\
Sur & $4 / 43(9.3)$ & 11.4 \\
\hline Total & $35 / 163(21.5)$ & 100 \\
\hline
\end{tabular}

muestreo.

Análisis del factor edad. Al analizar los resultados con relación a seropositividad versus edad, se determinó una ligera significancia estadística $\left(\chi^{2}: 5.83, p=0.054\right.$, $p \geq 0.05$ ), lo cual se podría interpretar como la existencia de una mayor frecuencia de infección dependiendo del intervalo de edad (Tabla 2).

Análisis del factor raza o cruce. En la tabla 
Tabla 2. Porcentaje de animales seropositivos y seronegativos a LVB según la edad.

\begin{tabular}{ccc}
\hline \multirow{2}{*}{ Grupo etáreo } & \multicolumn{2}{c}{ Positivos } \\
\cline { 2 - 3 } & No (\%) & $\%$ del total \\
\hline Entre 3 y 4 años & $6 / 53(11.3)$ & 17.1 \\
Entre 5 y 6 años & $11 / 50(22.0)$ & 31.4 \\
Más de 7 años & $18 / 60(30.0)$ & 51.4 \\
\hline Total & $35 / 163(21.5)$ & 100 \\
\hline
\end{tabular}

3 se observa que $9(25.7 \%)$ animales cebuínos, 25 (71.4\%) animales cruzados y $1(2.9 \%)$ del ganado europeo fueron positivos a LVB. El grado de asociación entre la variable raza y la seropositividad a LVB no fue significativo $\left(\chi^{2}: 5.59, p=0.061, p \geq 0.05\right)$;

Tabla 3. Distribución de frecuencia de animales seropositivos y seronegativos a LVB según la raza.

\begin{tabular}{ccc}
\hline \multirow{2}{*}{ Raza } & \multicolumn{2}{c}{ Positivos } \\
\cline { 2 - 3 } & No (\%) & \% del total \\
\hline Cebuíno & $9 / 71(12.7)$ & 25.7 \\
Cruzado & $25 / 87(28.7)$ & 71.4 \\
Europeo & $1 / 5(20.0)$ & 2.9 \\
\hline Total & $35 / 163(21.5)$ & 100 \\
\hline
\end{tabular}

por lo que la presencia de LVB no está asociada con la raza del animal.

Análisis del factor tipo de explotación. La asociación de los resultados observados en la tabla 4, reveló diferencias estadísticamente significativas en la variable tipo de explotación con LVB $\left(\chi^{2}: 8.695, \quad p=0.003\right.$, $\mathrm{p} \leq 0.05)$. El anterior resultado demuestra que existe una alta asociación entre la presentación de LVB en relación con el propósito zootécnico de la raza o el tipo de explotación, siendo mucho mayor, la frecuencia de infección en animales doble Tabla 4. Relación de la seropositividad a LVB con el tipo de explotación.

\begin{tabular}{lcc}
\hline \multirow{2}{*}{$\begin{array}{c}\text { Tipo de } \\
\text { Explotación }\end{array}$} & \multicolumn{2}{c}{ Positivos } \\
\cline { 2 - 3 } & No $(\%)$ & $\begin{array}{c}\% \text { del } \\
\text { total }\end{array}$ \\
\hline Carne & $6 / 63(9.5)$ & 17.1 \\
Doble Propósito & $29 / 100(29.0)$ & 82.9 \\
\hline Total & $35 / 163(21.5)$ & 100 \\
\hline
\end{tabular}

propósito en comparación con el ganado de carne.

Análisis del estado reproductivo. Al analizar el grado de correlación entre las variables citadas en la tabla 5 con la seropositividad a la LVB, los resultados no fueron significativos $\left(\chi^{2}: 3.167, p=0.205\right.$, $p \geq 0.05$ ) lo que en otras palabras, quiere decir

Tabla 5. Relación de la seropositividad a LVB con trastornos reproductivos.

\begin{tabular}{lcc}
\hline \multirow{2}{*}{$\begin{array}{c}\text { Trastorno } \\
\text { Reproductivo }\end{array}$} & \multicolumn{2}{c}{ Positivos } \\
\cline { 2 - 3 } & $9 / 40(22.5)$ & 37.5 \\
\hline Aborto & $13 / 92(14.1)$ & 54.2 \\
Repetidora & $2 / 5(4.0)$ & 8.3 \\
$\begin{array}{l}\text { Reabsorción } \\
\text { embrionaria }\end{array}$ & $24 / 137(17.5)$ & 100 \\
\hline Total & \multicolumn{2}{c}{} \\
\hline
\end{tabular}

que la presencia de reactividad a la LVB es independiente de los trastornos reproductivos considerados.

Asociación sexo - LVB. La investigación también arrojó algunos resultados concernientes a la influencia del macho con relación a la presencia de LVB en vacas. Como se puede observar en la tabla 6 , de 26 toros muestreados, 11 resultaron positivos (31.4\%), lo que indica asociación entre la presencia de LVB y el sexo $\left(\chi^{2}: 7.964, p=0.005, p \leq 0.05\right)$. El valor observado es altamente significativo, lo cual

Tabla 6. Relación del sexo con la seropositividad a LVB

\begin{tabular}{ccc}
\hline \multirow{2}{*}{ Sexo } & \multicolumn{2}{c}{ Positivos } \\
\cline { 2 - 3 } & No $(\%)$ & $\begin{array}{c}\% \text { del } \\
\text { total }\end{array}$ \\
\hline Hembra & $24 / 137(17.5)$ & 68.6 \\
Macho & $11 / 26(42.3)$ & 31.4 \\
\hline Total & $35 / 163(21.5)$ & 100 \\
\hline
\end{tabular}


podría estar relacionado con el mayor número de contactos del macho con hembras seropositivas a través de la monta natural.

\section{DISCUSIÓN}

Los resultados del estudio están de acuerdo con trabajos realizados en otras regiones, donde, la prevalencia de $24,9 \%$ encontrada para la región Andina, es superior a la encontrada en otras regiones de Colombia (9). Sin embargo, los resultados del presente estudio $(21 \%)$ están por encima de otros trabajos realizados en la costa norte: $1.5 \%$ en Córdoba (10) y 15\% en Cereté, San Carlos y Momil (11).

Al considerar los diferentes grados de correlación entre seropositividad a LVB y las variables analizadas, se encontró una relación significativa de la infección con la variable zona, posiblemente debido al mayor flujo de animales en la zona Este donde se encuentran dos subastas ganaderas que movilizan mucho ganado, dándose una mayor probabilidad de propagarse la enfermedad.

En cuanto al tipo de explotación el análisis de correlación reveló diferencias altamente significativas para el ganado doble propósito, el cual presentó un mayor grado de seropositividad. Esto se podría explicar por un mayor grado de contacto entre los animales y mayor manipulación de los mismos en este tipo de explotación (3).

En cuanto a la variable edad se encontró una ligera significancia, resultado que concuerda con estudios que reportan una prevalencia mayor de LVB en animales adultos (20), y que también podría ser explicado por una exposición acumulada a través de los años al contacto con animales infectados.
En este estudio se determinó que no hubo diferencias altamente significativas para las variables raza; ni correlación entre la presencia de la infección por la LVB y otros trastornos reproductivos tales como el aborto, repetición de servicios o reabsorción embrionaria. El hecho de haber encontrado una mayor frecuencia de LVB en vacas repetidoras $(54.1 \%)$, puede ser el resultado de la inclusión de mayor número de hembras repetidoras en el estudio. En otros estudios como el realizado en sistemas de producción de leche de la Sabana de Bogotá, se encontró, que vacas con infección de LVB, requerían más servicios por concepción (21).

De otro lado, la mayor positividad en los toros se puede explicar por un mayor número de contactos sexuales con hembras seropositivas y posibles secretoras del virus. Un ejemplo de la sospecha clínica y la verificación serológica de la infección en machos de la región, se observó durante la presente investigación, donde se encontraron lesiones características de LVB en un toro de la raza Brahman (zona sur) el cual mostró pérdida progresiva de peso y un aumento bilateral de los ganglios linfáticos explorables. El animal previamente resultó positivo a la prueba de ELISA, siendo este caso confirmativo de la presencia clínica de la LVB en la zona sur del municipio de Montería.

En conclusión el alto porcentaje de LVB (21\%) confirman la necesidad de establecer la detección de seroreactores como un diagnóstico de rutina y sugiere la necesidad de implementar programas de control y prevención, y de ser posible, erradicación de los animales infectados con el LVB. Esto 


\section{REFERENCI AS}

ayudaria a prevenir su diseminación y por ende las pérdidas económicas en la producción y reproducción de los animales.

1 Beer J. Enfermedades infecciosas de los animales domésticos. Tomo I. Zaragoza, España: Acribia; 1987.

2 Kohara J, Konnai S, Onuma $M$. Experimental transmission of Bovine leukemia virus in cattle via rectal palpation. J pn J Vet Res 2006; 54(1): 25-30.

3 Piper C, Prenatal and postnatal transmission of the bovine leukemia virus. In: Kirkbride, CA. Viral agents and associated lesions detected in a 10-year study of bovine abortions and stillbirths. J Vet Diagn Invest 1992; 4 : 374-379.

4 Blood DC, Radostis OM, Gay CC, Blood DG, Hinchcliff, KW. Medicina veterinaria. Tratado de las enfermedades del ganado bovino, ovino, porcino, caprino y equino. Tomo 2. Londres: Mc Graw Hill; 2002.

5 Rebhun WC. Enfermedades del Ganado vacuno lechero. Zaragoza, España: Acribia; 1999.

6 Mariño OC. Situación de la investigación en leucosis bovina en Colombia. Acovez $1984 ; 8(27)$ : 22-26.

7 Guy-Hyun Suh, Jeong-Chi Lee, ChaiYong Lee. Establishment of a bovine leukemia virus-free dairy herd in Korea. J Vet Sci 2005; 6(3): 227-230.

8 Shettigara PT, Samagh BS, Lovinowich EM. Eradication of bovine leukemia virus infection in commercial dairy herds using the agar gel immunodiffusion test. Can J Vet Res 1986; 50, 221-226.

9 Griffiths I, Gallego M, Villamil L. Factores de infertilidad y pérdidas económicas en ganado de leche en Colombia. Colombia: División de
Disciplinas Pecuarias, ICA; 1982.

10 Orjuela J, Navarrete M, Betancourt L. Salud y productividad en bovinos de la costa norte de Colombia ICA[en linea]. Colombia; 1991.URL disponible en http:/ /www.fao.org/ag/aga/agap/fig/ feedback/war/u9900bOg/htm.

11 Visbal S. Prevalencia serológica de leucosis viral bovina en algunas zonas del departamento de Córdoba Colombia. Rev MVZ Córdoba 1997; 21: $26-31$.

12 Nuotio L, Rusanen $\mathrm{H}$, Sihvonen L, Neuvonen E. Eradication of enzootic bovine leucosis from Finland. Prev Vet Med 2003; 59: 43-49

13 DiGiacomo R. The epidemiology and control of bovine leukemia virus infection. Vet Med 1992; 87: 248-257.

14 Ochoa AC, Uribe A, Gutierrez M. Estudio del potencial zoonótico del virus de la leucosis bovina y su presencia en casos de cáncer de seno. Univ Scient 2006; 11(2): 31-40.

15 Sandez N, Ilieva D, Sizov I, Rusenova $\mathrm{N}$, Iliev E. Prevalence of enzootic bovine leukosis in the Republic of Bulgaria in 1977-2004. Arch Vet 2006; 76(3): 263268.

16 Instituto Geográfico Agustin Codazzi (IGAC). Colombia: Dirección General del Instituto Geográfico; 2006.

17 Instituto Colombiano Agropecuario (ICA). Informe censo bovino II ciclo de vacunación aftosa - brucelosis. Reporte Anual Estadistico. Monteria. 2004.

18 Laboratorios IDEXX. Elisa de detección de los anticuerpos del virus de la leucosis viral bovina. Westbrook Maine 04092 USA 2003

19 Siegel S. Estadística no paramétrica aplicada a las ciencias de la conducta 
3 Ed. México: trillas; 2005.

20 Rehinhard G, Hochstein-Mintzel V, Riedemann S, Leal H, Neyda M. Estudio serológico de leucosis enzoótica bovina en un predio de la provincia de Valdivia y su relación a parámetros productivos y reproductivos. J Vet Med $\mathrm{B}$ Infect Dis Vet Public Health 1988; (35): 178-185.

21 García F, Calderón A, Almansa J, Garzón C, Márquez D, Jiménez G, Jaramillo F. Efectos de la infección por el virus de la leucosis bovina sobre la producción y reproducción en un hato lechero. Revista FMVZ 2000; 47(2): 39-44. 